\title{
A NEW METHOD OF METAL TEMPERATURE ESTIMATION FOR SERVICE-RUN BLADES AND VANES
}

\author{
K. A. Ellison, J. A. Daleo, K. Hussain \\ BWD Turbines Limited \\ 1-601 Tradewind Dr., Ancaster, Ontario L9G 4V5
}

Keywords: SICOAT 2453, phase transformations, temperature estimates

\begin{abstract}
A NiCoCrAlYRe overlay coating, SICOAT 2453* exhibited a series of solid state transformations involving five equilibrium phase fields between room temperature and $1200^{\circ} \mathrm{C}$. The largest changes in $\gamma, \gamma^{\prime}$ and $\beta$ phase fraction (over $50 \mathrm{v} / \mathrm{o}$ for $\gamma$ and $\gamma^{\prime}$ ) occurred in the temperature range $815^{\circ} \mathrm{C}$ to $970^{\circ} \mathrm{C}$. These changes are potentially useful for metallurgical service temperature estimation, as they occur within the operating range of many combustion turbine blades and vanes. A phase fraction vs. temperature diagram was developed for SICOAT 2453 and used to estimate the local metal operating temperatures of a servicerun, single crystal PWA 1483 alloy first stage blade and a polycrystalline first stage MAR M 509 turbine vane coated with the NiCoCrAlYRe alloy. The strengths and limitations of the new temperature estimation method are discussed and compared to older methods of obtaining metal temperature estimates from service-run blades and vanes.
\end{abstract}

\section{Introduction}

Life assessment of turbine hot section components is a complex process involving non-destructive evaluations, metallurgical analysis of representative components and finite element modeling for temperature and stress analysis. When available, metallurgical temperature estimates from service-exposed blades and vanes can be used to improve the accuracy of finite element heat transfer models that support component life and repair limit calculations.
Two methods are commonly used by materials engineers to estimate the local service operating temperatures of nickel-based superalloy turbine components. These models are based on the rates of (a) gamma prime coarsening in precipitationstrengthened, nickel-based superalloys [1,2], and (b) CoCrAlY or CoNiCrAlY coating - substrate diffusion zone growth [3] and/or the depletion rate of $\beta-\mathrm{NiAl}$ from the coating itself [4]. Both methods are widely used and, when properly applied, have proven to be very useful tools for metallurgical life assessment of service-run blades and vanes. However, the first method cannot be applied in the analysis of cobalt-based superalloys, since they do not form the gamma prime strengthening phase. Furthermore, the diffusion zone growth/beta depletion technique has proven difficult to apply for certain NiCoCrAlY coating types, because interdiffusion is limited, the interdiffusion zone microstructures are complex and undergo significant constitutional changes over the range of service operating temperatures. Finally, both methods of temperature estimation require or assume that the subject blade or vane has operated for thousands of hours at a constant load level, which is often not the case.

A recently introduced commercial coating for which the above issues apply is SICOAT 2453, a proprietary NiCoCrAlYRe coating of Siemens, AG [5]. Measurements of SICOAT 2453 beta phase depletion over the temperature range $865^{\circ} \mathrm{C}$ to $1050^{\circ} \mathrm{C}$ have shown that the rate of beta phase recession in the coating does not follow a simple parabolic relationship, as is the case for many other MCrAlY coating systems [6]. This finding was attributed to the changes in diffusion zone microstructure which have been reported over the same temperature range $[7,8]$. Due to the limitations described above, alternative methods for obtaining metal temperature estimates from service-run blades and vanes coated with SICOAT 2453 were needed. This paper describes the results of further investigations into the phase changes that occur in SICOAT 2453 and their application to metallurgical temperature estimation.

\footnotetext{
* SICOAT 2453 is a designation of Siemens AG, Power Generation (KWU), Mülheim, Germany
} 


\section{$\underline{\text { Experimental Procedures }}$}

Differential Scanning Calorimeter (DSC) measurements were performed on samples of SICOAT 2453 alloy powder using a Netzsch STA 409 PC apparatus. A pure Ni reference sample of nearly identical mass was used as a reference standard and for background subtraction. The DSC measurements were performed by heating at $15^{\circ} \mathrm{C} / \mathrm{min}$ from room temperature to $1250^{\circ} \mathrm{C}$ and then cooling the sample at $15^{\circ} \mathrm{C} / \mathrm{min}$ to $500^{\circ} \mathrm{C}$.

The SICOAT 2453 coating material was also evaluated on IN 738, PWA1483 SX and MAR M 509 alloy substrates. The nominal compositions of the coating and substrate alloys are provided in the Table below. The non service-run coating on the IN 738 blade sample was applied by a low pressure plasma spray (LPPS) method, and then heat treated at $1120^{\circ} \mathrm{C}$ for 2 hours followed by $845^{\circ} \mathrm{C}$ for 24 hours. The coated IN-738 blade was sectioned into bars measuring approximately $100 \mathrm{~mm} \times 10 \mathrm{~mm} \times$ $3 \mathrm{~mm}$. The bars, with type $\mathrm{K}$ thermocouples spot welded to each end, were placed into a three-zone tube furnace which was adjusted to produce linear temperature gradients $\left( \pm 15^{\circ} \mathrm{C}\right)$ between $350^{\circ} \mathrm{C}$ and $1250^{\circ} \mathrm{C}$. The bars were held at temperature for between 2 to 100 hours and then air cooled. The bars were sectioned, mounted and polished for optical and scanning electron microscopy (SEM). The polished coating samples were etched in $1 \% \mathrm{CrO} 3$ acid solution at 6VDC and examined under a Zeiss ICM405 light microscope. Digital photomicrographs were obtained followed by quantitative analysis of individual phases in each of the samples. Phase identification was also performed using a Link Analytical QX2000 analyzer attached to a Phillips 515 scanning electron microscope with URSA acquisition and analysis software. The quantitative analysis system was calibrated using a pure $\mathrm{Cu}$ standard.

\begin{tabular}{|c|c|c|c|c|}
\hline \multicolumn{5}{|c|}{ TABLE I. Nominal composition (w/o) of coating and substrate alloys. } \\
\hline & SICOAT 2453 & IN 738 & PWA 1483 SX & MAR M 509 \\
\hline $\mathrm{Ni}$ & Bal. & Bal. & Bal. & 10.0 \\
\hline $\mathrm{Co}$ & 12.0 & 8.5 & 9 & Bal. \\
\hline $\mathrm{Cr}$ & 21.2 & 16.0 & 12.8 & 23.4 \\
\hline $\mathrm{Al}$ & 11.0 & 3.4 & 3.6 & - \\
\hline $\mathrm{Ti}$ & - & 3.4 & 4.0 & 0.2 \\
\hline $\mathrm{Mo}$ & - & 1.75 & 1.9 & - \\
\hline $\mathrm{W}$ & - & 2.6 & 3.8 & 7.0 \\
\hline $\mathrm{Ta}$ & - & 1.75 & 4 & 3.5 \\
\hline $\mathrm{Nb}$ & - & 0.85 & - & - \\
\hline $\mathrm{Zr}$ & - & 0.12 & - & 0.5 \\
\hline $\mathrm{B}$ & - & 0.012 & - & - \\
\hline $\mathrm{C}$ & - & 0.13 & - & 0.6 \\
\hline $\mathrm{Re}$ & 1.7 & - & - & - \\
\hline $\mathrm{Y}$ & 0.5 & - & - & - \\
\hline
\end{tabular}

The service-run SICOAT 2453 coating on the PWA1483 SX blade was evaluated in the as-received condition after approximately 3000 equivalent operating hours (EOH) of operation in a V84.3A combustion turbine. Similarly, the coating on the MAR M 509 vane was evaluated in the service-run condition after less than 5000 fired hours of base-load operation in a V84.3A combustion turbine. In each case, the SICOAT 2453 coating was applied by LPPS and functioned as the bond coat of a two-layer thermal barrier coating (TBC) system.

\section{Results}

DSC Analysis

Heating and cooling thermograms for SICOAT 2453 alloy powder are shown in Figure 1. A small exothermic peak was observed in the cooling thermogram with an onset at approximately $860^{\circ} \mathrm{C}$ and a maximum at approximately $820^{\circ} \mathrm{C}$. As will be shown in the following section, this exotherm was associated with the precipitation of $\gamma^{\prime}$ phase. The $\gamma^{\prime}$ solvus temperature was represented by the right hand side of the exothermic peak at $860^{\circ} \mathrm{C}$, while the maximum rate of $\gamma^{\prime}$ formation occurred at $815^{\circ} \mathrm{C}$ [9]. In contrast, the corresponding endothermic peak on the heating thermogram was very broad and poorly defined.
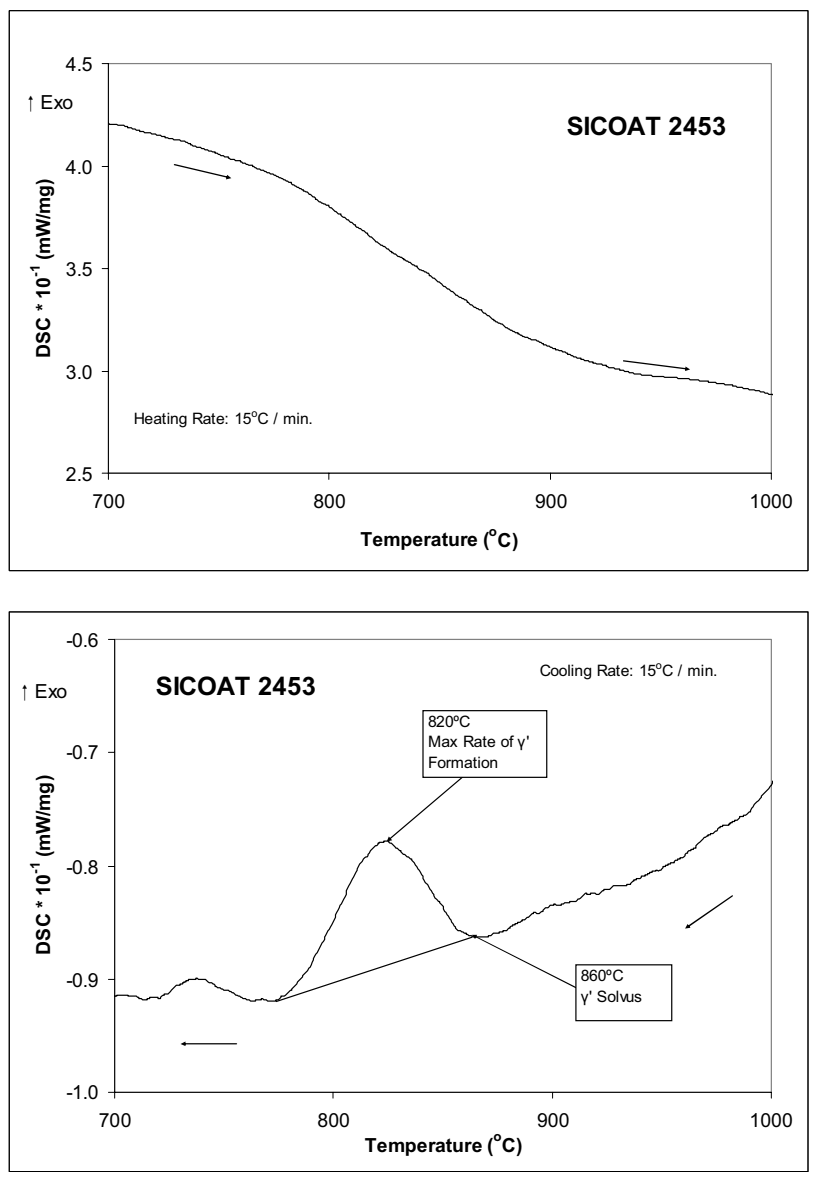

Figure 1. DSC data for SICOAT 2453 powder.

Furnace Annealed Bars

Optical and scanning electron micrographs corresponding to selected areas of the air cooled gradient furnace bars are provided in Figures 2 to 5. The area shown in Figure 2 corresponded to an annealing temperature of $1210 \pm 15^{\circ} \mathrm{C}$. This region of the bar was comprised of only two phases: $\gamma$ and $\beta$. The beta phase, which appears light (unetched) in these images, accounted for approximately $45 \mathrm{v} / \mathrm{o}$ of the total. The compositions of the individual phases are shown in Table II. 


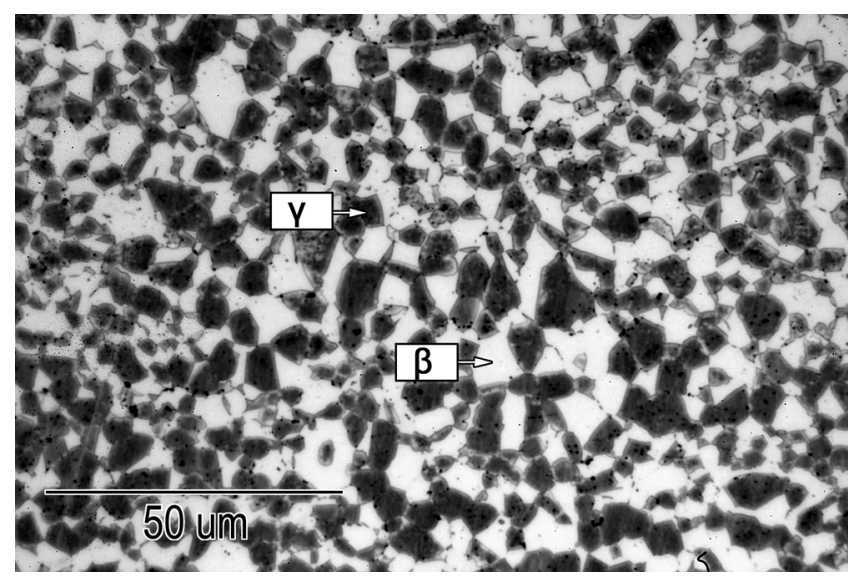

Figure 2. Optical micrograph of SICOAT 2453 annealed $2 \mathrm{~h}$ at $1210^{\circ} \mathrm{C}$

\begin{tabular}{|c|c|c|c|c|c|c|}
\hline \multicolumn{7}{|c|}{$\begin{array}{l}\text { TABLE II. Composition (a/o) of SICOAT } 2453 \text { Phase } \\
\text { Constituents at } 1210^{\circ} \mathrm{C}\end{array}$} \\
\hline Phase & $\mathrm{Ni}$ & Co & $\mathrm{Cr}$ & $\mathrm{Al}$ & $\mathrm{Re}$ & $\mathrm{Cr}+\mathrm{Re}$ \\
\hline$\gamma$ & 52 & 11 & 22 & 15 & 0.5 & 22.5 \\
\hline$\beta$ & 51 & 6 & 10 & 33 & & 10 \\
\hline
\end{tabular}

The area shown in Figure 3 corresponds to an annealing temperature of $1155 \pm 15^{\circ} \mathrm{C}$. This region of the bar was comprised of three phases: $\gamma, \beta$ and approximately $3 \mathrm{v} / \mathrm{o}$ of chromium-rich $\alpha_{\mathrm{Cr}}$ phase dispersed as angular globules within and adjacent to the $\beta$ phase. Note that the $\alpha_{\text {Cr }}$ phase contained a relatively high concentration of rhenium $(17 \mathrm{a} / \mathrm{o})$, Table III. The $1 \%$ chromic acid solution again etched the $\gamma$ phase preferentially, and did not significantly dissolve the $\beta$ and $\alpha_{\mathrm{Cr}}$ phases. The unetched $\alpha_{\mathrm{Cr}}$ grains were very reflective (white) under the optical microscope and produced high atomic number contrast in backscattered electron images.

The area shown in Figure 4 corresponded to an annealing temperature of $860 \pm 15^{\circ} \mathrm{C}$. This region of the bar was comprised of four phases: $\gamma, \beta, \alpha_{\mathrm{Cr}}$, and $\sigma$. The $\sigma$ phase comprised approximately $10 \mathrm{v} / \mathrm{o}$ of the structure, while the $\alpha_{\mathrm{Cr}}$ content was reduced to approximately $1 \mathrm{v} / \mathrm{o}$. It was also noteworthy that the volume fraction of beta phase increased to approximately $60 \mathrm{v} / \mathrm{o}$, while the amount of gamma phase decreased to approximately 27 v/o. As shown in Table IV, some of the rhenium partitioned to the $\sigma$ phase (approximately $8 \mathrm{a} / \mathrm{o}$ ), at the expense of the rhenium in the $\alpha_{\text {Cr }}$ phase (approximately $13 \mathrm{a} / \mathrm{o}$ ). The $1 \%$ chromic acid solution etched the $\sigma$ phase less aggressively than the $\gamma$ phase (darkest in the OM images), and again left the $\beta$ and $\alpha_{\mathrm{Cr}}$ phases essentially untouched.

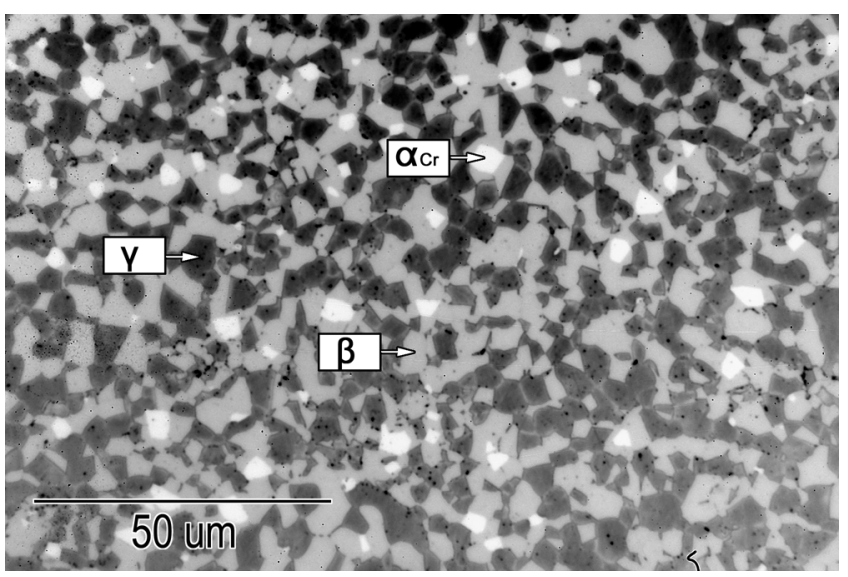

Figure 3. Optical micrograph of SICOAT 2453 annealed $2 \mathrm{~h}$ at $1155^{\circ} \mathrm{C}$.

\begin{tabular}{|c|c|c|c|c|c|c|}
\hline \multicolumn{7}{|c|}{$\begin{array}{l}\text { TABLE III. Composition (a/o) of SICOAT } 2453 \text { Phase } \\
\text { Constituents at } 1155^{\circ} \mathrm{C}\end{array}$} \\
\hline Phase & $\mathrm{Ni}$ & Co & $\mathrm{Cr}$ & $\mathrm{Al}$ & $\mathrm{Re}$ & $\mathrm{Cr}+\mathrm{Re}$ \\
\hline$\gamma$ & 49 & 12 & 23 & 15 & 1 & 24 \\
\hline$\beta$ & 51 & 7 & 9 & 33 & & 9 \\
\hline$\alpha_{\mathrm{Cr}}$ & 5 & 2 & 76 & & 17 & 93 \\
\hline
\end{tabular}

Due to the slight etching effect, the edges of the $\sigma$ grains were more sharply defined than the $\alpha_{\text {Cr }}$ grains. Nevertheless, both of these phases remained highly reflective (white) under the optical microscope.

The microstructure shown in Figure 5 corresponded to an annealing temperature of $760 \pm 15^{\circ} \mathrm{C}$. This region of the bar was comprised of five phases: $\gamma, \gamma^{\prime}, \beta, \alpha_{\mathrm{Cr}}$ and $\sigma$. Comparing these images to those shown in Figure 4, revealed that major changes in coating microstructure had taken place. The most pronounced change was the presence of over $50 \mathrm{v} / \mathrm{o}$ of $\gamma^{\prime}$ phase. The $\gamma^{\prime}$ formed at the expense of $\gamma$ and $\beta$, as the latter were reduced to approximately $5 \mathrm{v} / \mathrm{o}$ and $30 \mathrm{v} / \mathrm{o}$, respectively. The single phase $\gamma^{\prime}$ grains were located between adjacent grains of $\gamma$ and $\beta$.

The boundaries between adjacent grains of $\gamma^{\prime}$ and $\beta$ were less distinct than those between $\gamma^{\prime}$ and the other phases. This was because the $1 \%$ chromic solution did not significantly attack either of the $\gamma^{\prime}$ and $\beta$ phases. Under the optical microscope, the $\gamma^{\prime}$ phase appeared light gray whereas the $\beta$ phase was slightly darker. Conversely, the $\gamma$ phase was deeply etched, while etching of the $\alpha_{\mathrm{Cr}}$ and $\sigma$ phases was as described above. The composition of the individual phases identified in Figure 5 is given in Table V. 


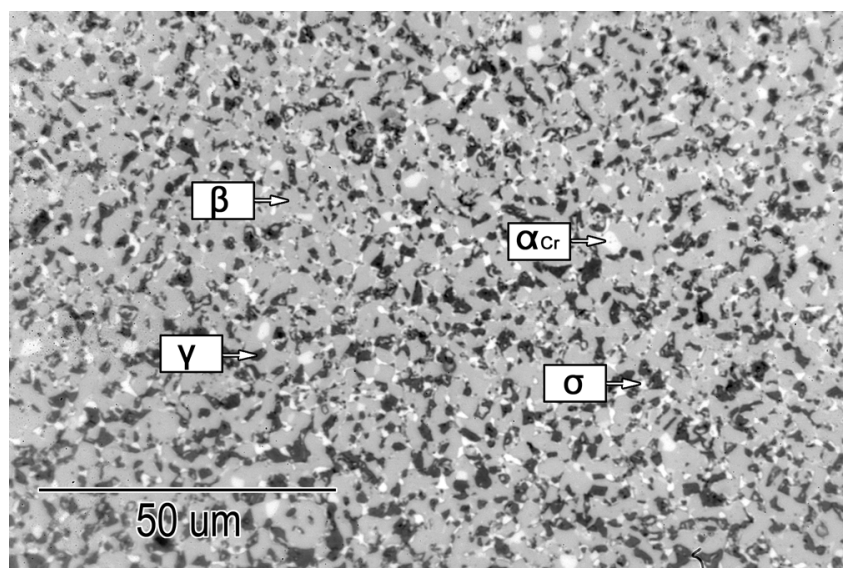

(a)

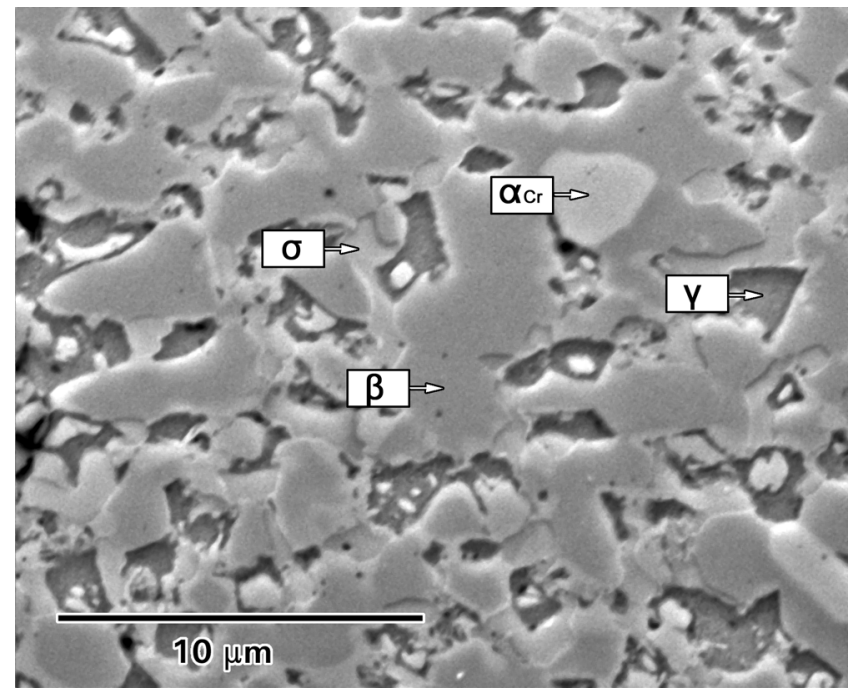

(b)

Figure 4. (a) Optical and (b) SEM images of SICOAT 2453 annealed $24 \mathrm{~h}$ at $860^{\circ} \mathrm{C}$.

\begin{tabular}{|c|c|c|c|c|c|c|}
\hline \multicolumn{7}{|c|}{$\begin{array}{l}\text { TABLE IV. Composition (a/o) of SICOAT } 2453 \text { Phase } \\
\text { Constituents at } 860^{\circ} \mathrm{C} \text {. }\end{array}$} \\
\hline Phase & $\mathrm{Ni}$ & $\mathrm{Co}$ & $\mathrm{Cr}$ & $\overline{\mathrm{Al}}$ & $\mathrm{Re}$ & $\mathrm{Cr}+\mathrm{Re}$ \\
\hline$\gamma$ & 46 & 15 & 25 & 12 & 2 & 27 \\
\hline$\beta$ & 52 & 5 & 5 & 38 & & 5 \\
\hline$\alpha_{\mathrm{Cr}}$ & 10 & 3 & 71 & 3 & 13 & 84 \\
\hline$\sigma$ & 22 & 15 & 49 & 5 & 8 & 57 \\
\hline
\end{tabular}

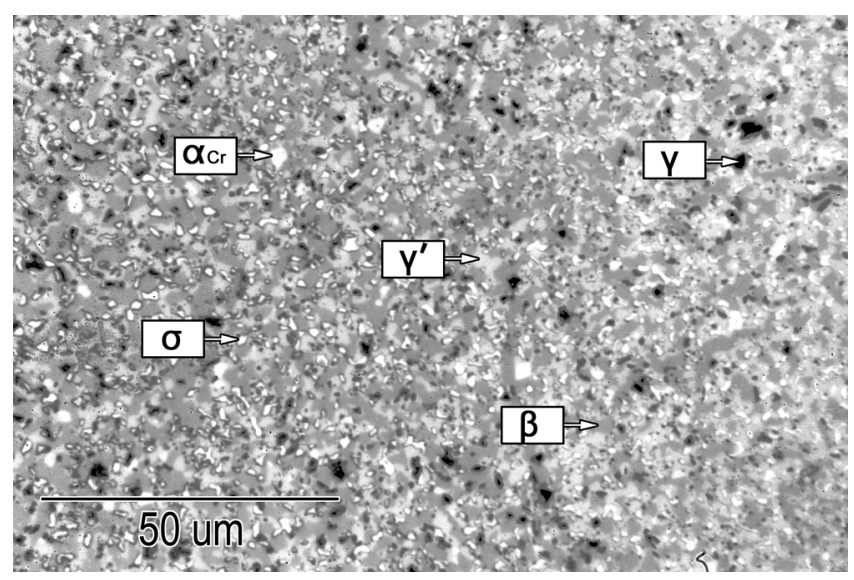

(a)

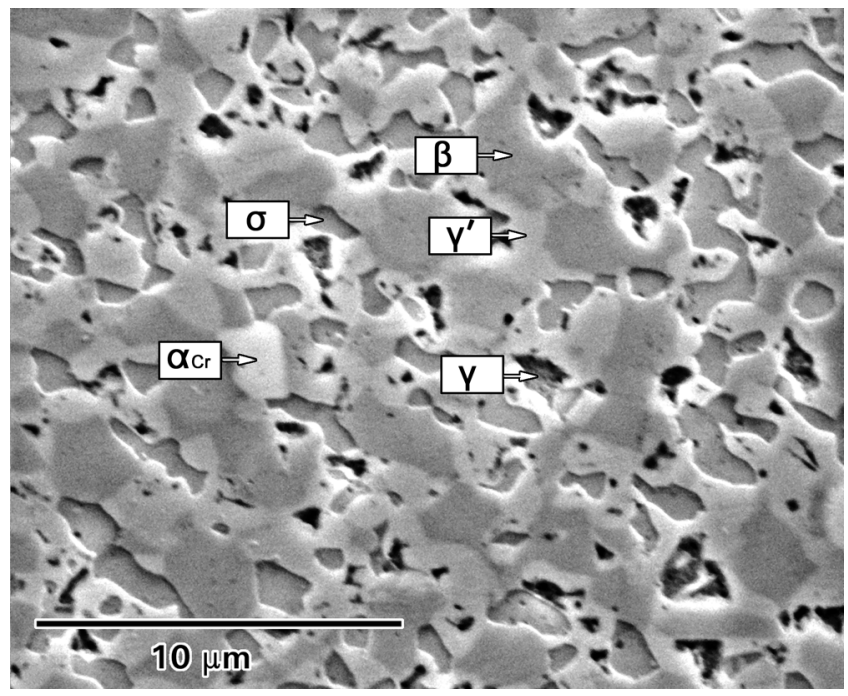

(b)

Figure 5. (a) Optical and (b) SEM images of SICOAT 2453 annealed $24 \mathrm{~h}$ at $760^{\circ} \mathrm{C}$.

TABLE V. Composition (a/o) of SICOAT 2453 Phase Constituents at $760^{\circ} \mathrm{C}$.

\begin{tabular}{|l|l|l|l|l|l|l|}
\hline Phase & $\mathrm{Ni}$ & $\mathrm{Co}$ & $\mathrm{Cr}$ & $\mathrm{Al}$ & $\mathrm{Re}$ & $\mathrm{Cr}+\mathrm{Re}$ \\
\hline$\gamma$ & 47 & 14 & 25 & 14 & & 25 \\
\hline$\gamma^{\prime}$ & 59 & 9 & 10 & 22 & & 10 \\
\hline$\beta$ & 51 & 6 & 7 & 36 & & 7 \\
\hline$\alpha_{\mathrm{Cr}}$ & 12 & 3 & 76 & 2 & 7 & 83 \\
\hline$\sigma$ & 22 & 18 & 52 & 6 & 2 & 54 \\
\hline
\end{tabular}




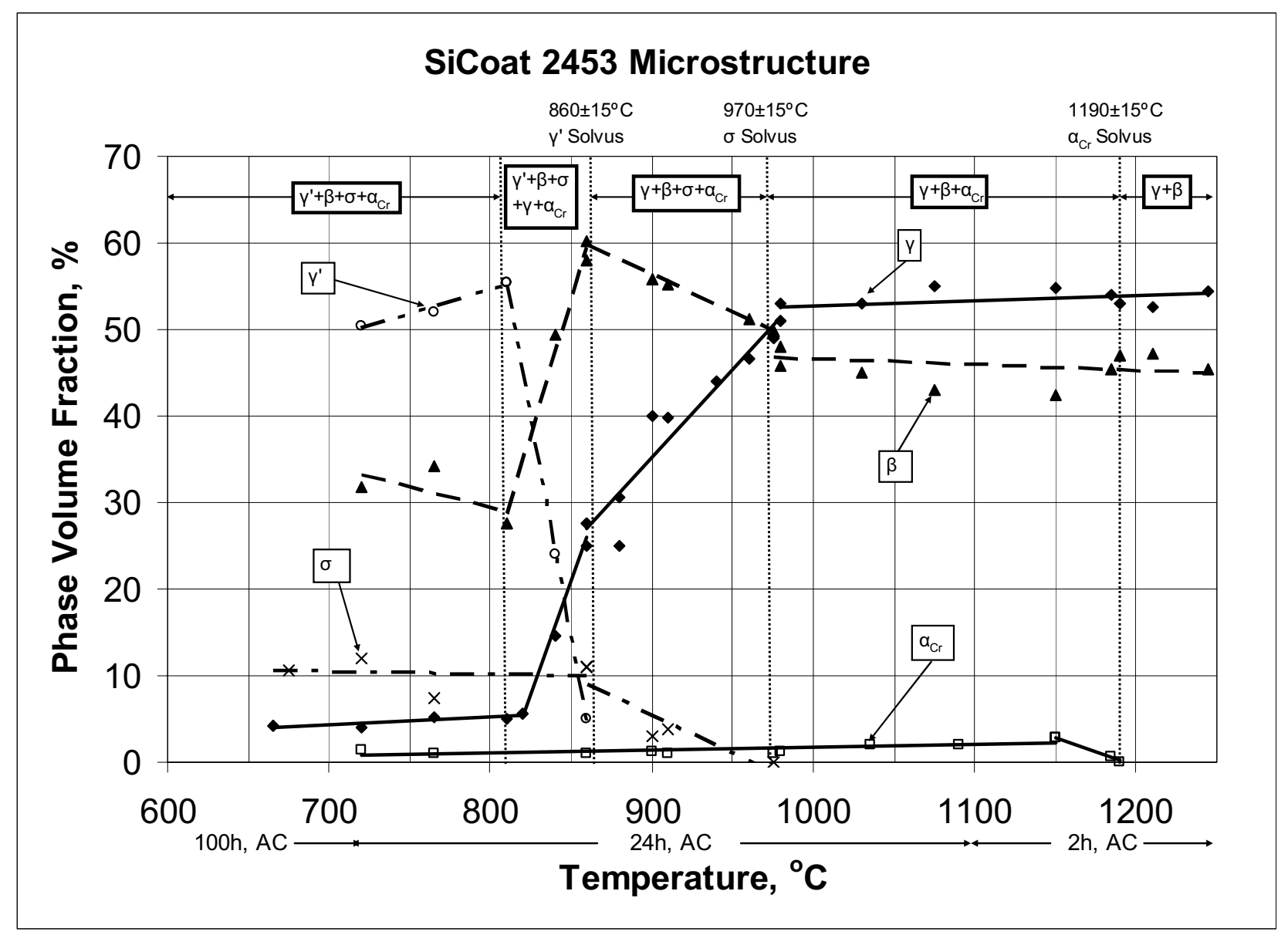

Figure 6. Phase fraction vs. temperature diagram for SICOAT 2453.

\section{SICOAT 2453 Volume Fraction vs. Temperature Diagram}

The volume fraction of the five principal coating phases described in the previous section was determined by quantitative image analysis at additional locations along the air cooled gradient furnace bars. The results are presented as a phase fraction vs. temperature diagram in Figure 6. Due to the estimated experimental errors associated with the use of the gradient bars, the temperatures on the horizontal axis are accurate to within $\pm 15^{\circ} \mathrm{C}$.

Between room temperature and $1200^{\circ} \mathrm{C}$ SICOAT 2453 displayed a series of solid state phase transformations involving five equilibrium phase fields. Above $970^{\circ} \mathrm{C}$ the bulk coating comprised roughly equal amounts of $\gamma$ and $\beta$-NiAl, plus a minor amount of $\alpha_{\mathrm{Cr}}$. As the temperature decreased from approximately $970^{\circ} \mathrm{C}$ to $860^{\circ} \mathrm{C}$ the volume fraction of $\gamma$ matrix phase was reduced from approximately $50 \mathrm{v} / \mathrm{o}$ to $25 \mathrm{v} / \mathrm{o}$, while $\beta-\mathrm{NiAl}$ increased to $60 \mathrm{v} / \mathrm{o}$ and $\sigma$ appeared. These results were in agreement with previously reported data on the microstructure of the SICOAT 2453 coating at temperatures between $865^{\circ} \mathrm{C}$ and $1050^{\circ} \mathrm{C}[6,7]$.
As temperatures were further reduced from $860^{\circ} \mathrm{C}$ to $815^{\circ} \mathrm{C}$, the remaining $\gamma$ matrix phase was progressively replaced by $\gamma^{\prime}$ phase, with a corresponding reduction in the volume fraction of the $\beta$ $\mathrm{NiAl}$ phase to approximately $30 \mathrm{v} / \mathrm{o}$. Note that the temperature range for the $\gamma^{\prime}$ transformation observed in the gradient bars was in good agreement with the position of the exothermic peak in the DSC cooling thermogram, Figure 1. Note also that, although the gradient furnace bars showed the presence of a small residual amount $(\leq 5 \mathrm{v} / \mathrm{o})$ of $\gamma$ phase at temperatures below about $815^{\circ} \mathrm{C}$, the low temperature region of the phase fraction diagram has been identified on the diagram as $\gamma^{\prime}+\beta+\alpha_{\mathrm{Cr}}+\sigma$. The reasons for this will be discussed below. 


\section{Effect of Slow Cooling on SICOAT 2453 Microstructure}

The effect of reducing the cooling rate on SICOAT 2453 microstructure was examined by cooling a coating sample at $10^{\circ} \mathrm{C} / \mathrm{min}$ from $1200^{\circ} \mathrm{C}$ to below $800^{\circ} \mathrm{C}$, followed by a water quench. The corresponding coating microstructure is shown in Figure 7. In this sample, discrete $\gamma^{\prime}$ grains were not observed. Instead, nucleation of fine $(<0.2$ micron $) \gamma^{\prime}$ precipitates took place within the $\gamma$ grains. In some areas, the fine $\gamma^{\prime}$ precipitates had begun to agglomerate into continuous structures, but the pretransformation $\gamma$ grain size and volume fraction could still be ascertained. The percentages of the various phase constituents were: $48 \pm 2 \mathrm{v} / \mathrm{o} \gamma+\gamma^{\prime}$ (prior $\gamma$ ), $51 \pm 2 \mathrm{v} / \mathrm{o} \beta$ and $1-2 \%$ of $\alpha_{\mathrm{Cr}}$.

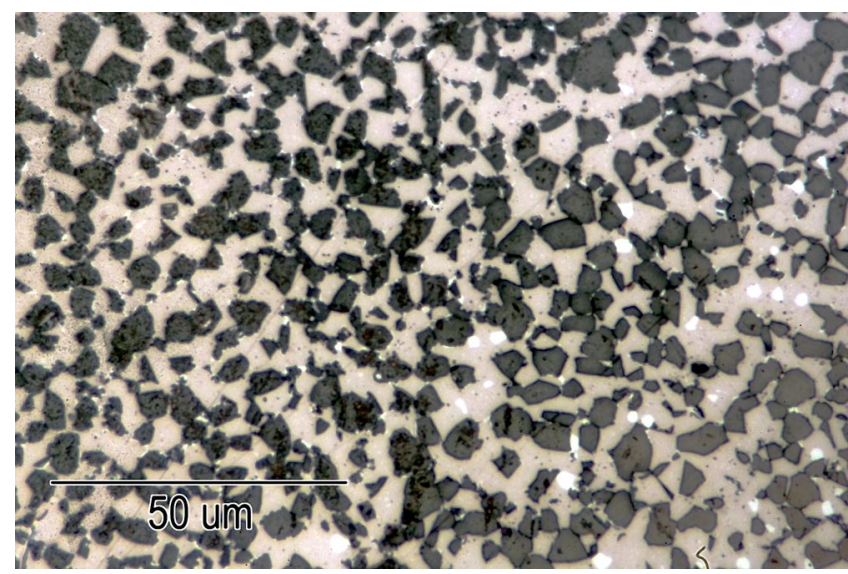

(a)

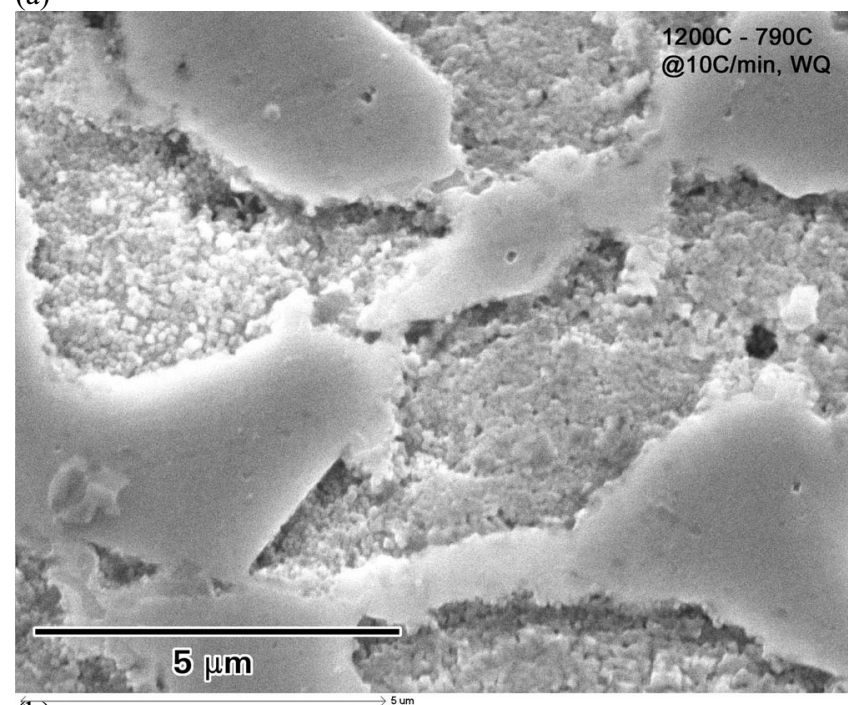

(b)

Figure 7. (a) Optical and (b) SEM images of the SICOAT 2453 microstructure after cooling from $1200^{\circ} \mathrm{C}$ to $790^{\circ} \mathrm{C}$ at $10^{\circ} \mathrm{C} / \mathrm{min}$. followed by water quench. $\underline{\text { Service-Run MAR M } 509 \text { First Stage Vane }}$

SICOAT 2453 is currently used as a bond coat for the TBC coating system applied to the blades and vanes in Siemens V84.3A and V94.3A industrial gas turbines (IGT). It is also being used as a "stand-alone" overlay coating on blades and vanes of the V84.2 IGT. A V84.3A first stage vane, manufactured from MAR M 509 alloy with SICOAT 2453 TBC bond coat is shown in Figure 8. The vane was removed from the turbine after less than 5000 hours of service.

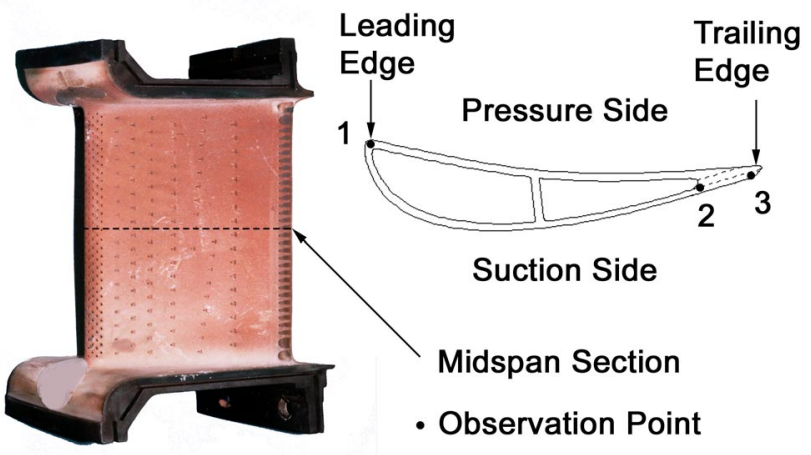

Figure 8. Service-run V84.3A row 1 turbine vane.

Over most of the airfoil surface, the coating was comprised of four phases: $\gamma^{\prime}, \beta, \alpha_{\mathrm{Cr}}$ and $\sigma$, (no $\gamma$ ) corresponding to temperatures below $815 \pm 15^{\circ} \mathrm{C}$. Examples of this are shown in Figures 9 and 10. The absence of $\gamma$ phase in the service-exposed coating was taken as evidence that $\gamma$ is unstable in SICOAT 2453 at low temperatures and that it will completely transform to $\gamma^{\prime}$ at hold times longer than what was used to expose the gradient furnace test bars. This finding, along with the sharp break in the v/o $\gamma$ and $\gamma^{\prime}$ phases vs. temperature curves at around $815^{\circ} \mathrm{C}$ are the reasons why the low temperature phase field of Figure 6 was labeled as $\gamma^{\prime}$, $\beta, \alpha$ and $\sigma$. The larger grain size at observation point 2 was taken as evidence that point 2 was operating closer to $815^{\circ} \mathrm{C}$ than observation point 1 .

In contrast, a localized area at the airfoil trailing edge contained approximately 24 v/o $\gamma$ in addition to $\gamma^{\prime}, \beta, \alpha_{\mathrm{Cr}}$ and $\sigma$, Figure 11. The volume fraction of $\gamma, \gamma^{\prime}$ and $\beta$ was essentially uniform throughout the thickness of the coating at this location. Referring to Figure 6, the TBC bond coat temperature was estimated to be $860^{\circ} \mathrm{C} \pm 15^{\circ} \mathrm{C}$ at observation point 3 .

The metallurgical temperature estimates were in reasonable agreement with independent predictions from a finite element heat transfer model (FEM). The V84.3A row 1 vane is generally well cooled, and steady state operating temperatures over most of the airfoil midspan section were estimated to be below $815^{\circ} \mathrm{C}$ $\left(1500^{\circ} \mathrm{F}\right)$, Figure 12 . However, the FEM predicted that metal temperatures would increase rapidly at the airfoil trailing edge. Note that, although the maximum FEM temperature was higher than that derived from the coating microstructure, the combustor profile and heat transfer boundary conditions at the airfoil trailing edge are very difficult to predict. 

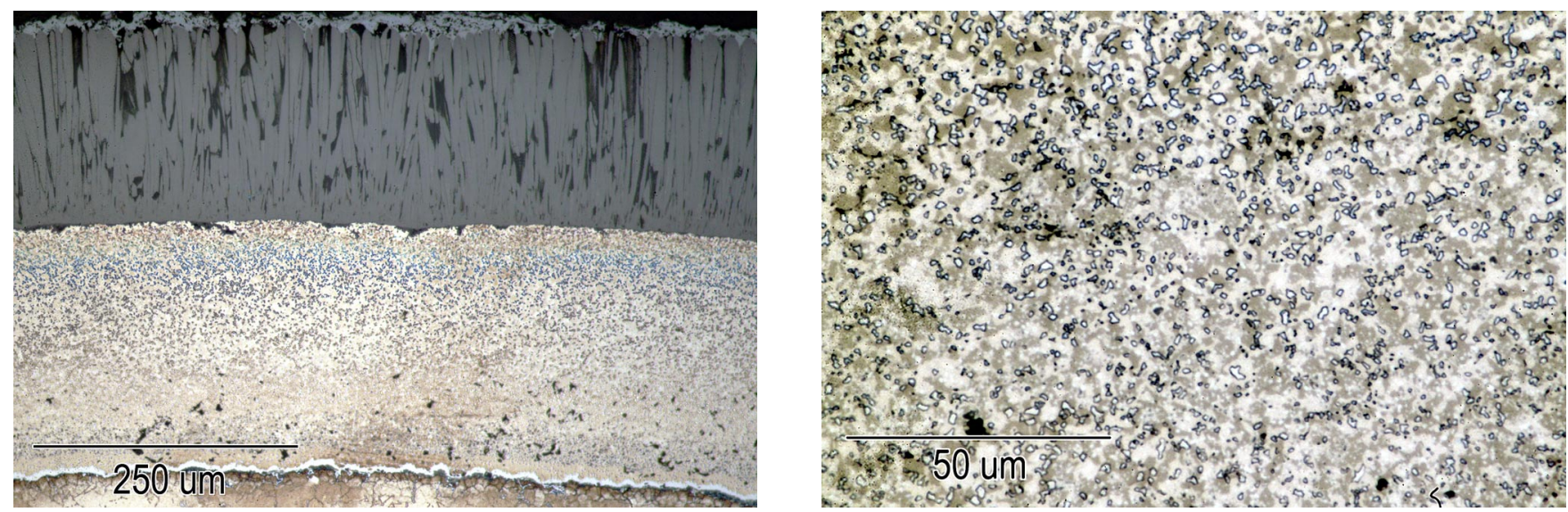

Figure 9. Optical micrographs showing the condition of the SICOAT 2453 bond coat at observation point 1 of Figure 8.
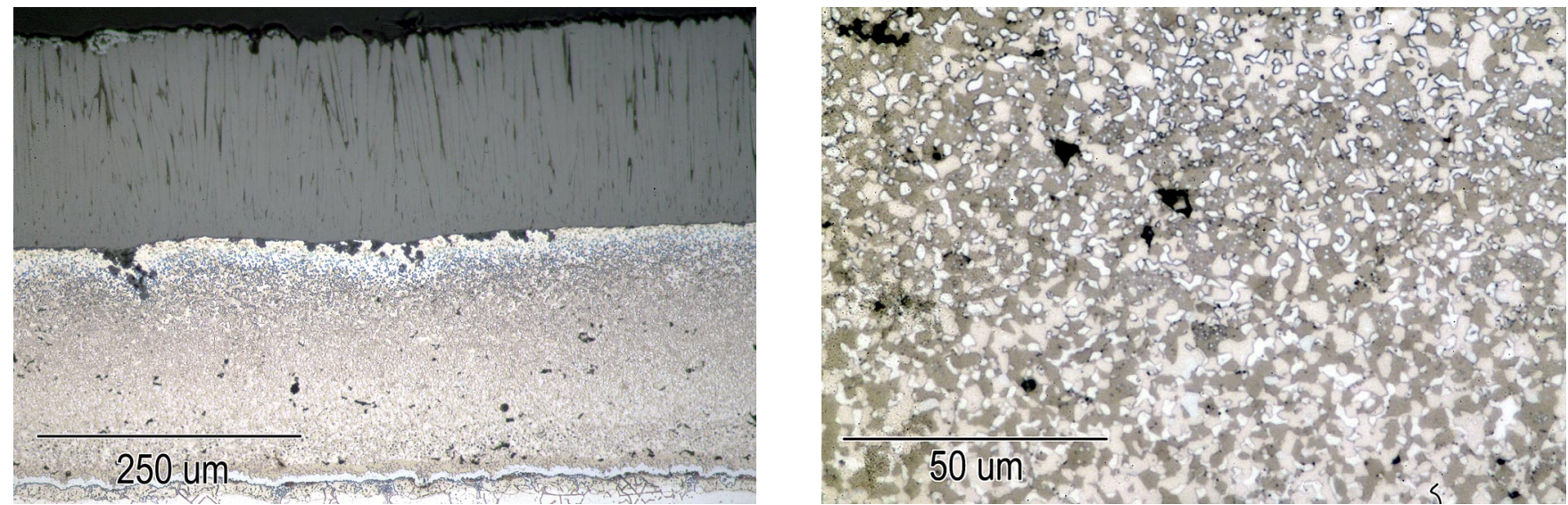

Figure 10. Optical micrographs showing the condition of the SICOAT 2453 bond coat at observation point 2 of Figure 8.
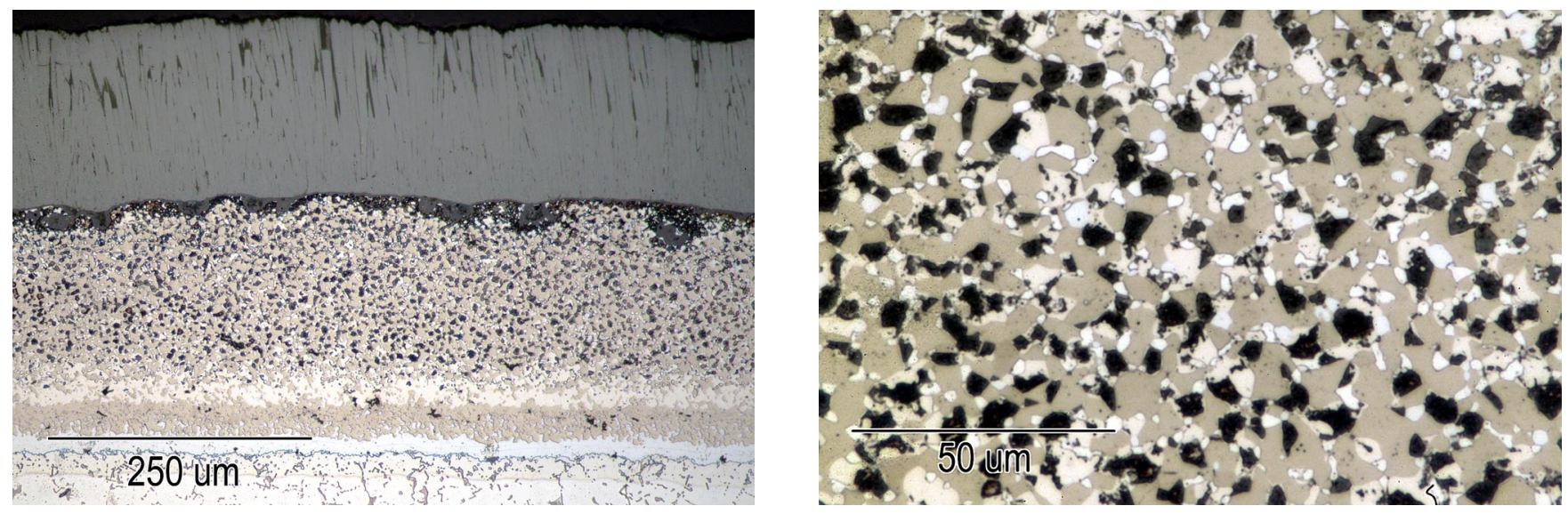

Figure 11. Optical micrographs showing the condition of the SICOAT 2453 bond coat at observation point 3 of Figure 8. 


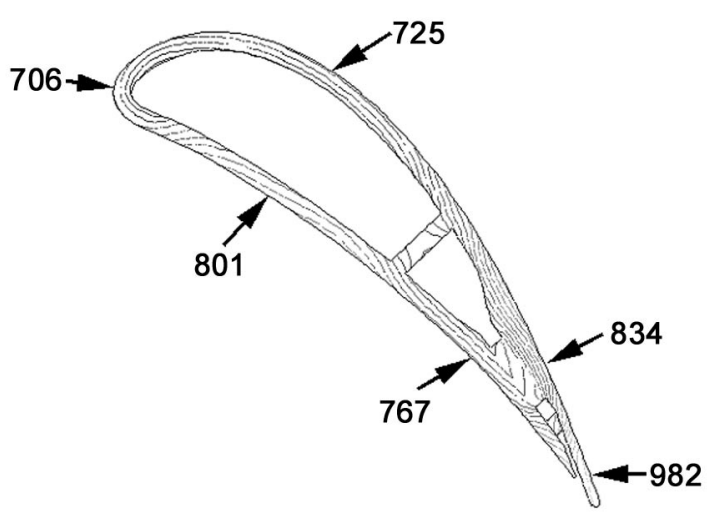

Figure 12. Plot of the calculated steady-state temperatures (in Celsius degrees) in the V84.3A TLe1 vane airfoil cross-section at the midspan location.

\section{$\underline{\text { Service-Run PWA } 1483 \text { SX First Stage Blade }}$}

A V84.3A first stage blade was removed from service after approximately $3000 \mathrm{EOH}$ to determine why the thermal barrier topcoat had spalled off the pressure side of the airfoil and whether or not the other components in the set could safely operate to the next scheduled overhaul (Figure 13). The temperature distribution in the airfoil, with and without the TBC coating, was needed to make this decision. The TBC coating system consisted of an EBPVD partially stabilized $\left(6-8 \% \mathrm{Y}_{2} \mathrm{O}_{3}\right)$ zirconia top coat applied onto the SICOAT 2453 bond coating. The coating failure occurred at the bond coat/top coat interface but the length of time that the blade had been operating in this condition was not known. Due to the low number of fired hours, and uncertainties regarding the time since the coating spall had occurred, it was not possible to use the gamma prime growth method to estimate local metal operating temperatures.
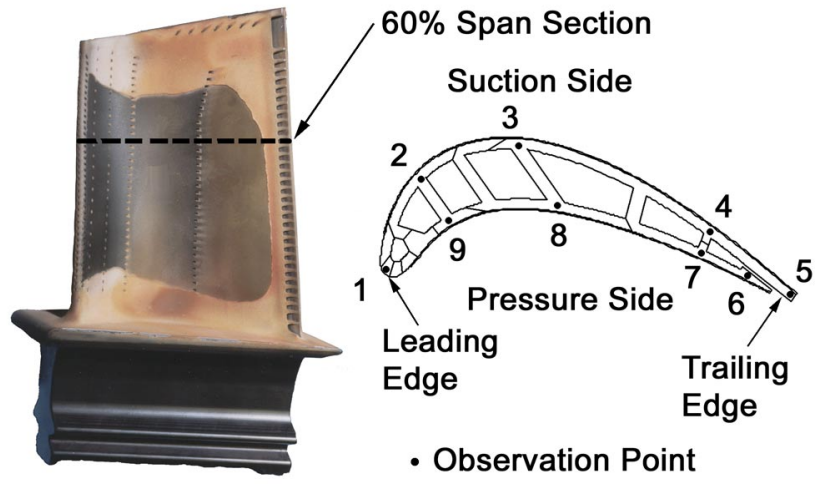

- Observation Point

Figure 13. Service-run V84.3A turbine blade.

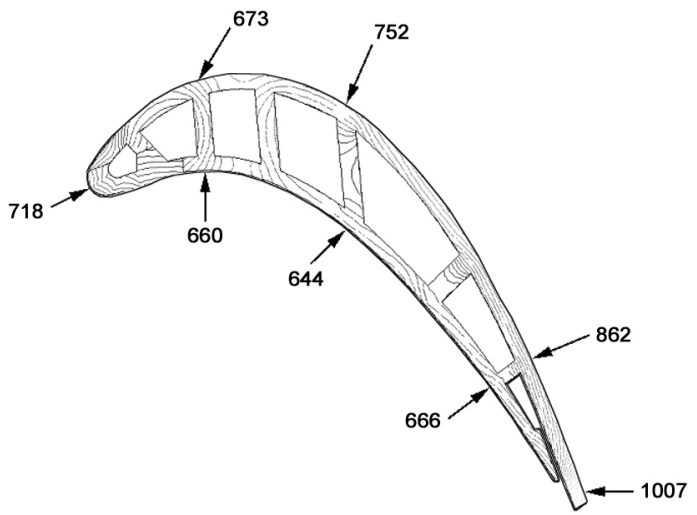

Figure 14. Plot of the calculated steady-state temperature distribution (in Celsius degrees) in the V84.3A TLe1 blade airfoil cross-section at the midspan location with no TBC on the airfoil pressure side.

A finite element heat transfer model was created to assess the effects of the TBC spall on the airfoil temperature distribution. The calculated temperature profile at 50 percent height with no $\mathrm{TBC}$ on the airfoil pressure side is shown in Figure 14. In spite of the fact that the ceramic top coat was missing, the FEM predicted that metal temperatures would be below about $760^{\circ} \mathrm{C}\left(1400^{\circ} \mathrm{F}\right)$ everywhere except at the airfoil trailing edge.

The metallurgical analysis showed that at observation points 1 to 4, 8 and 9 the SICOAT 2453 coating was comprised of four phases: $\gamma^{\prime}, \beta, \alpha_{\mathrm{Cr}}$ and $\sigma$, (no $\gamma$ ) corresponding to temperatures below $815 \pm 15^{\circ} \mathrm{C}$. An example of the microstructure at observation point 8 is shown in Figure 15. At locations 5 to 7 , the coating contained approximately $5 \% \gamma$, in addition to $\gamma^{\prime}, \beta, \alpha_{\mathrm{Cr}}$ and $\sigma$, Figure 16, corresponding to surface temperatures of approximately $825 \pm 15^{\circ} \mathrm{C}$. Once again, the agreement between the model predictions and metallurgical estimates was judged to be reasonable, taking into account the uncertainties involved in the FEM calculations.

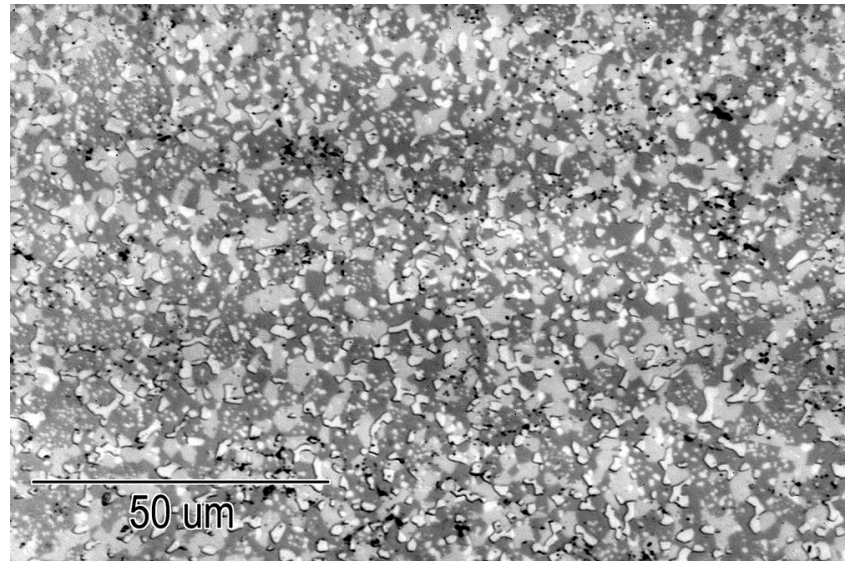

Figure 15. Optical micrograph showing the condition of the SICOAT 2453 bond coat at observation point 8 of Figure 13. 


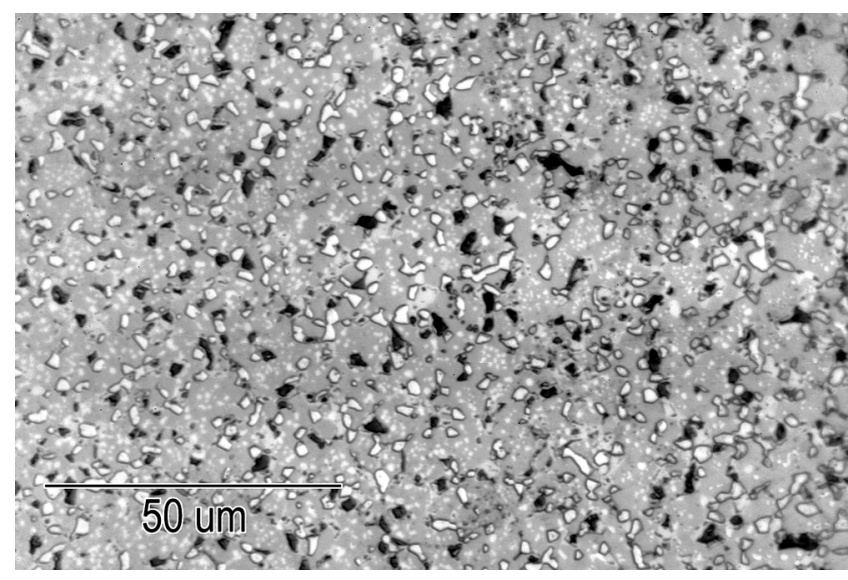

Figure 16. Optical micrograph showing the condition of the SICOAT 2453 bond coat at observation point 5 of Figure 13.

\section{Discussion}

The results of this investigation showed that large scale changes in $\gamma, \gamma^{\prime}$ and $\beta$ volume fraction occurred in the SICOAT 2453 alloy over the temperature range from approximately $815^{\circ} \mathrm{C}$ to $970^{\circ} \mathrm{C}$. This behavior is somewhat unusual, but not unique among commercially applied IGT MCrAlY coatings. Most CoCrAlY and CoNiCrAlY coatings (Co $>50 \mathrm{w} / \mathrm{o})$ in IGT service have a relatively simple and stable microstructure comprised primarily of $\beta$-(NiCo)Al precipitates in a $\gamma$ matrix phase [10]. In contrast, NiCrAlY coatings with aluminum contents above about $12 \mathrm{w} / \mathrm{o}$ are known to undergo a $\gamma+\beta \leftrightarrow \gamma^{\prime}+\alpha_{\mathrm{Cr}}$ transformation at $990^{\circ} \mathrm{C}$ [11]. Between these two extremes are the Ni-rich NiCoCrAlY alloys. In the 1970's, Pratt \& Whitney Aircraft developed a series of NiCoCrAlY alloys based on the chemistry Ni-20Co-18Cr12Al-0.2Y [12] [13]. One of the resulting commercial alloys, designated PWA 276: Ni-20.3Co-17.3Cr-13.6Al-0.5Y (w/o) was reported to form fine ( 0.05 micron diameter) gamma prime inside the gamma phase after a 32 hour annealing treatment at $870^{\circ} \mathrm{C}$ [14]. A modified version of this alloy, PWA286 [15]: Ni-21Co17Cr-12Al-0.6Y-0.3Si-0.15Hf (w/o) exhibited a $\gamma^{\prime}+\beta$ microstructure after annealing for 24 hours at $800^{\circ} \mathrm{C}$ [16]. This structure transformed to $\gamma+\beta$ upon annealing for 3 hours at $1100^{\circ} \mathrm{C}$. Thus, it appears that $\gamma^{\prime}+\beta \leftrightarrow \gamma+\gamma^{\prime}+\beta \leftrightarrow \gamma+\beta$ transformations may allow service temperature estimates to be made for other NiCoCrAlY alloy systems. A detailed analysis of phase changes in the PWA 286 coating system will be the subject of a future research program.

As shown by the V84.3A row 1 blade and vane examples, "benchmark" estimates based on the $\gamma^{\prime}$ and $\sigma$ solvus temperatures can be quickly and easily obtained from a qualitative analysis of the coating microstructure. Surface temperatures can also be calculated between $815^{\circ} \mathrm{C}$ and $970^{\circ} \mathrm{C}$, based on quantitative image analysis of the volume fraction of $\gamma, \gamma^{\prime}$ and $\beta$ in the coating. An analysis of the errors involved showed that the uncertainty in estimated metal temperatures would be approximately $\pm 15^{\circ} \mathrm{C}$ from $815^{\circ} \mathrm{C}$ to $860^{\circ} \mathrm{C}$ and $\pm 20^{\circ} \mathrm{C}$ from $860^{\circ} \mathrm{C}$ to $970^{\circ} \mathrm{C}$. These temperature estimation "windows" and uncertainties are comparable to those typically quoted for the gamma prime growth and coating interdiffusion methods. Of particular significance, was the ability to use this method of temperature estimation on a cobalt-based superalloy substrate and on a blade where significant changes in operating temperature were known to have occurred during the operating life of the part.

It is important to recognize that the observed coating phase changes are reversible under normal engine operating conditions. As such, the coating microstructure and associated temperature estimates will be representative of the recent operating conditions of the part, but not necessarily the long term average. This will be beneficial for situations such as failure investigations (as demonstrated by the first stage blade example) and short term engine tests to validate design temperature predictions. Furthermore, the long term operating history of the engine, i.e. total number of fired hours and load levels, is not necessarily required in order to apply this method of temperature estimation. However, sufficient time at temperature is required to bring the coating microstructure into an equilibrium condition. At $800^{\circ} \mathrm{C}$, the required hold time is estimated to be in the range of 16 to 24 hours, which is typical of IGT units in cycling duty. The hours per start would typically be longer than this for base load units, but shorter for peaking units.

This contrasts with earlier methods of metallurgical temperature estimation involving gamma prime growth or coating beta phase depletion. The latter processes are not reversible under normal engine operating conditions, and thousands of service hours are typically required to produce measurable changes in microstructure at these temperatures. In addition, knowledge of the long term operating history of the engine is required in order to apply the associated temperature estimation models and correctly interpret the results.

A limitation on the use of overlay coating microstructure to estimate service temperatures is that irreversible changes in bulk coating composition will occur after long term service due to inward and outward diffusion of coating elements. These changes will become more pronounced with increasing temperature and time of exposure. This means that temperature estimates will not be reliable in areas where significant changes in coating composition have occurred due to (1) oxide scale formation near the outer coating interface and (2) interdiffusion with the underlying blade or vane alloy near the inner coating interface. However, this possibility can be easily assessed on service-run blade and vane samples by comparing the bulk coating composition in hot and cold areas of the part using SEM/EDXS techniques. Furthermore, depletion of coating elements results in composition gradients within the coating layer, with visually observable effects such as depletion of beta phase at the inner and outer surfaces. In contrast, constitutional changes brought about by temperature variations alone should produce a more uniform microstructure throughout the thickness of the coating, as seen on the V84.3A row 1 vane and blade. Fortunately, NiCoCrAlY coatings such as SICOAT 2453 and PWA 286 exhibit excellent oxidation resistance and microstructural stability as compared to CoNiCrAlY and CoCrAlY overlay coatings [5].

In contrast, cooling rate effects should not present significant limitations on the use of this temperature estimation method. During a normal shutdown, the first stage blade and vane cooling rates in "E" and " $F$ " class industrial gas turbines are typically between $10-20^{\circ} \mathrm{C} / \mathrm{min}$. During a forced shutdown (full load trip) the cooling rates are much higher. However, the present results showed that samples cooled at $10^{\circ} \mathrm{C} / \mathrm{min}$ from above the $\gamma^{\prime}$ solvus 
temperature did not exhibit significant differences in the volume fraction of $\gamma$ and $\beta$ phase, relative to air cooled samples.

\section{Conclusions}

The volume fractions of $\gamma, \gamma^{\prime}$ and $\beta$ phases in SICOAT 2453, a NiCoCrAlYRe overlay coating, change continuously with temperature between $815^{\circ} \mathrm{C}$ and $970^{\circ} \mathrm{C}$.

The phase fraction vs. temperature diagram for this coating can be used to estimate local surface metal operating temperatures of service-run blades and vanes.

Metallurgical temperature estimates derived from coating phase changes compliment those available from the gamma prime growth, beta phase depletion and coating inter-diffusion models. The new temperature estimation method is independent of the base alloy the coating is applied onto thus it is applicable to both cobalt and nickel based components. Detailed analysis of coating phase changes can also provide valuable insight into the short term operating conditions of the part.

\section{Acknowledgements}

Mr. Jim Wilson of BWD Turbines Limited and Mr. Ian Hunter are acknowledged for providing the finite element models of blade and vane heat transfer. The authors are also grateful to Mr. Jim Garrett and Mr. Frank Gibbs of McMaster University, Hamilton, Ontario, Canada, for assistance with sample preparation and DSC analysis. Financial support for this work was provided, in part, by the National Research Council of Canada, Industrial Research Assistance Program.

\section{References}

1. D.J. Chellman, and A.J. Ardell, "The Coarsening of $\gamma^{\prime}$ Precipitates at Large Volume Fractions", Acta Metallurgica, 22 (1974), 577-588.

2. R.A. Stevens, and P.E.J. Flewitt, "The Effects of $\gamma^{\prime}$ Precipitate Coarsening During Isothermal Aging and Creep of the Nickel-Base Superalloy IN-738", Materials Science and Engineering, 37 (1979), 237-247.

3. K.A. Ellison, J.A. Daleo, and D.H. Boone, "Metallurgical Temperature Estimates Based on Interdiffusion Between CoCrAlY Overlay Coatings and a Directionally Solidified Nickel-Base Superalloy Substrate," Materials for Advanced Power Engineering 1998, ed. J. Lecomte-Beckers et al. (Julich, Germany: Forschungszentrum Julich GmbH Central Library, 1998), 1523-1534.

4. V. Srinivasan, N.S. Cheruvu, T.J. Carr, and C.M. O'Brien, "Degradation of MCrAlY Coating and Substrate Superalloy During Long Term Thermal Exposure", Materials and Manufacturing Processes, 10 (1995), 955969.
5. N. Czech and F. Schmitz, U.S. Patent 5,154,885, "Highly Corrosion And/Or Oxidation-Resistant Protective Coating Containing Rhenium”, 1992.

6. Y. Itoh and M. Tamura, "Reaction Diffusion Behaviours for Interface Between Ni-Based Super Alloys and Vacuum Plasma Sprayed MCrAlY Coatings", Journal of Engineering for Gas Turbines and Power, 121, (1999) 476-483.

7. K.A. Ellison and J.A. Daleo, "Microstructural Evaluation of MCrAlY / Superalloy Interdiffusion Zones", Life Assessment of Hot Section Gas Turbine Components, ed. R. Townsend et al. (London, UK: The Institute of Materials, Edinburgh, 2000), 311-327.

8. K.A. Ellison, J.A. Daleo, and D.H. Boone, "Interdiffusion Behaviour in NiCoCrAlY Re-Coated IN738 at $940^{\circ}$ and $1050^{\circ}$, Superalloys 2000, ed. T.M. Pollock et al. (Warrendale, PA: The Minerals, Metals and Materials Society, 2000), 649-654.

9 . D.L. Sponseller, "Differential Thermal Analysis of Nickel-base Superalloys", Superalloys 1996, ed. R.D. Kissinger et al. (Warrendale, PA: The Minerals, Metals and Materials Society, 1996) 259-270.

10. P. Mazars, D. Manesse and C. Lopvet, "Degradation of MCrAlY Coatings by Interdiffusion, Paper 87-GT-58, Proceedings of ASME Turbo Expo 2003, May 31 - June 4, 1987 Anaheim, California, USA, 5p.

11. S.M. Merchant and M.R. Notis, "A Review: Constitution of the Al-Cr-Ni System", Materials Science and Engineering, 66 (1984) 47-60.

12. R.J. Hecht, G.W. Goward and R.C. Elam, U.S. Patent 3,928,026, "High Temperature NiCoCrAlY Coatings", 1975.

13. D.K. Gupta and D.S. Duval, "A Silicon and Hafnium Modified Plasma Sprayed MCrAlY Coating", Superalloys 1984, ed. M. Gell et al. (Warrendale, PA: The Minerals, Metals and Materials Society, 1984), 711-720.

14. J. Gayda, T.P. Gabb and R.V. Miner, "Low Cycle Fatigue Behaviour of a Plasma-Sprayed Coating Material", Int. J. Fatigue, 8 (1986) 217-223.

15. D.K. Gupta and D.S. Duvall, U.S. Patent 4,419,416, “Overlay Coatings For Superalloys”, 1983.

16. T. Rehfeldt et al., "Order-Disorder Transformation in a NiCoCrAlY Bond Coat Alloy at High Temperature", Scripta Mater. 43 (2000) 963-968. 